\title{
José Gutiérrez, el arquitecto malagueño del neoclásico en Guadalajara, México (1766-1835)
}

\author{
Adriana Ruiz Razura \\ Universidad de Guadalajara (México)
}

CES.XVIII, núm. 18 (2008), págs. 181-210. 


\section{Resumen:}

El arquitecto José Gutiérrez impone un nuevo estilo arquitectónico en Guadalajara, Jalisco, México, el neoclásico, en tres edificios emblemáticos que cambian la imagen urbana del centro de la ciudad. Es también el primer docente de arquitectura en la Nueva Galicia, como se le conociera durante la Colonia al estado de Jalisco. Parecería que estos atributos fueran suficientes para reconocer su trayectoria académica y profesional, sin embargo la realidad es otra. Poco es lo que se sabe de él, y esto se constató con más de 100 encuestas realizadas entre arquitectos, académicos universitarios y público en general, quienes contestaron en un $80 \%$ no haber nunca escuchado al mencionado arquitecto.

La Casa de la Misericordia (actualmente Hospicio Cabañas), el templo del Sagrario Metropolitano, y el pórtico del ex templo de Santo Tomás (actualmente la Biblioteca Iberoamericana Octavio Paz), son las edificaciones construidas por el arquitecto Gutiérrez, aparte de obra pública como el Puente Verde, remodelaciones de templos en Guadalajara y Zacatecas, así como algunos proyectos de supervisión en la ciudad de México, constituyen parte del trabajo realizado.

Vivió momentos de grandes conflictos políticos y sociales, como lo fue el movimiento de la Independencia, por lo que pareciera su vida una serie de contradicciones y conflictos uno tras otro. Sin embargo y a pesar de los altibajos, su tenacidad y perfeccionismo como académico no pueden discutirse, su capacidad innovadora dentro de un nuevo estilo y su valentía al cambiar la imagen urbana de una ciudad provinciana en tres edificios emblemáticos de la misma.

Palabras clave: Neoclásico. Academia. Edificaciones. Nueva Galicia. 
A José María Gutiérrez López le tocó vivir una época difícil de transición, de movimientos armados, de cambios de mentalidad y eso se vio reflejado en su vida y en su obra. Como español participa en el movimiento de la Independencia, es el primer maestro de arquitectura en el Occidente de México, y mantiene un criterio y rigidez academicista que se denotará en todas sus construcciones. Introduce en Guadalajara el neoclásico en la arquitectura, y construye tres edificios públicos significativos que cambian la imagen urbana de la ciudad: La Casa de la Misericordia (hoy Hospicio Cabañas), el templo del Sagrario Metropolitano y el pórtico del ex templo de Santo Tomás (hoy Biblioteca Iberoamericana Octavio Paz). Con esta trayectoria profesional, nos preguntamos:

¿Cómo es que se conoce tan poco de él y no se le reconocen sus méritos y aportaciones arquitectónicas?

Con el objeto de fundamentar la anterior premisa se realizaron encuestas entre profesores de arquitectura, alumnos de arquitectura y público en general, y causó gran asombro el comprobar que más del $80 \%$ de los profesores de la licenciatura de arquitectura no lo conocen (se encuestaron 100 profesores), no saben que él fue el constructor del Cabañas y el diseñador y constructor del Sagrario Metropolitano y del pórtico de la Biblioteca Iberoamericana, y mucho menos saben que fue el primer profesor de arquitectura en Guadalajara.

¿Cómo entonces queremos que se le reconozca, si los académicos universitarios ignoran su existencia?

Realizando una búsqueda en la Biblioteca Pública Juan José Arreola, la Biblioteca Álvarez del Castillo, la de los centros universitarios de la UDG, del Iteso, y del TEC, la del Colegio de Jalisco, no encontramos ni un libro, ni una investigación que trate específicamente de este arquitecto. Algunos historiadores del siglo pasado, como Alberto Santoscoy ${ }^{1}$, Cornejo Franco ${ }^{2}$ y Pérez Ver-

1 Pedro José María Alberto Santoscoy Hernández, 1857-1906, historiador tapatío que se distinguió por su interés en el estudio y enseñanza de la historia de Jalisco. Entre su obra publicada se encuentra: Obras completas, tt. I y II, Guadalajara, Gobierno del Estado de Jalisco, 1984, 1986; Historia de Nuestra Señora de San Juan de los Lagos y del culto de esta milagrosa imagen, 1924; La Introducción de la Imprenta en Guadalajara, 1993.

2 José Cornejo Franco (1900-1977) nació en Tepatitlán. Realiza sus estudios en Guadalajara, participa en grupos literarios, primero en la Sociedad Enrique González Martínez, fundada por su maestro Agustín Basave. Más tarde colaboró con destacados intelectuales jaliscienses como Alfonso Gutiérrez Hermosillo, Agustín Yáñez, en el grupo Banderas de Provincias que publicó la revista con el mismo nombre, donde escribe varios 
día ${ }^{3}$, lo mencionan en dos o tres renglones, y recientemente se le escucha muy escuetamente, en investigadores como Justino Fernández, Arturo Camacho, Carmen Sotos, Elizabeth Fuentes, por lo que esto da la pauta para realizar una investigación más a detalle de la vida de este arquitecto.

En el plano gubernamental, tampoco se le reconoce, esto lo constatamos en la Guía Turística del Estado de Jalisco, publicada en 1999 por el Instituto Nacional de Estadística, Geografía e Informática (INEGI), donde se menciona que el pórtico de la Biblioteca Iberoamericana Octavio Paz, fue construido en 1826, por el ingeniero Manuel Gómez Ibarra. Error garrafal, ya que este ingeniero, aunque fue discípulo de José Gutiérrez, es a su maestro al que se le encomienda el nuevo pórtico del edificio que ocuparía el Congreso del Estado, utilizando lo que había sido el templo de la Compañía de Jesús ${ }^{4}$.

¿Cómo queremos que se le reconozca si a nivel gubernamental tampoco se le conoce?

Afortunadamente el panorama no es tan negro, en el Archivo del Arzobispado de Guadalajara, se encuentran las bitácoras de la construcción del Sagrario Metropolitano, y en el Archivo de la Academia de San Carlos, en la ciudad de México, también existe documentación suficiente para permitirnos esbozar un perfil de su personalidad y de su labor como profesional de la arquitectura. La búsqueda ha sido difícil, por la escasez de información que se tiene, sin embargo esto constituye un reto.

\section{El inicio de una aventura}

El primer indicio que encontramos de la infancia y juventud de Gutiérrez es como alumno de la Academia de San Fernando, fundada en 1752 en Madrid, donde aparece inscrito el 24 de enero de $1784^{5}$. Según lo comenta Carmen

ensayos como: «El centenario de Vigil», «Teatro religioso»y «Biobibliografía de Fray Servando». En 1931, el rector de la UDG Enrique Díaz de León, lo nombra director de la Biblioteca Pública del Estado, puesto que ocupó hasta su muerte. Ingresó el 8 de mayo de 1950 en la Academia Mexicana de la Historia, presentando un trabajo sobre la vida y obra de fray Luis del Refugio Palacio y Basave. Posteriormente ingresa en la Academia Mexicana de la Lengua y en 1957 la Universidad de Guadalajara lo distingue con el título de Maestro Honorario Vitalicio.

3 Luis Pérez Verdía (1857) nació en Guadalajara, estudió en el Liceo de Varones y en la Escuela de Jurisprudencia, donde obtuvo el título de abogado. Fue maestro del Liceo, enseñó Historia y Cronología. Fue diputado local y federal tres veces y diplomático. Escribió varias obras, entre ellas una Biografía de Prisciliano Sánchez e Historia Particular del Estado de Jalisco, t. II, Guadalajara, Editorial Gráfica, 1952.

4 Estado de Jalisco, México, Guía turística, INEGI, México, 1999, pág.101.

5 A.B.A.M: Libro de matrículas de los discípulos de la Academia de San Fernando, desde principios de año, 1784, en Carmen Soto Serrano, Los pintores de la expedición de Alejandro Malaspina, t. I, Madrid, Real Academia de la Historia, 1982, págs. 151-154. 
Sotos, en el libro de matrícula de la mencionada Academia, se dice que es natural de Málaga, y sitúa su nacimiento alrededor de 1770. Al respecto Alberto Santoscoy menciona como lugar de su nacimiento Benaque, pueblo del obispado de Málaga, a fines de 1772 o muy al principio de 1773. Igualmente menciona que sus padres fueron don Lorenzo Gutiérrez y doña Ana López ${ }^{6}$. Estos datos son incorrectos, como lo constataremos en el acta de defunción del arquitecto, de donde comprobamos que él nace en $1766^{7}$.

A los alumnos más aventajados de la Academia se les estimulaba con una pensión para radicar en el extranjero, la mayoría de las veces en Roma, donde los dos primeros años teóricos asistían a clases de matemáticas, geometría, mecánica, hidrostática, perspectiva, trigonometría, secciones cónicas y de montea, así como el estudio de los teóricos de la arquitectura: Vitrubio, Alberti, Perrault, Serlio, Vignola, Palladio y Scamozzi, y entre los españoles, Arfe, Fray Lorenzo de San Nicolás, Caramuel y Tosca. Los siguientes dos años los dedicaban a la visita de los edificios antiguos y modernos de Roma y sus alrededores, con el consiguiente dibujo de los mismos, en estricto apego a medidas y proporciones. En teoría los últimos dos años estaban dedicados a realizar un viaje por varios países, lo que por razones económicas no siempre se realizaba ${ }^{8}$. Seguramente José Gutiérrez se ganó una de estas pensiones y decidió probar fortuna en la Nueva España, en vez de proseguir sus estudios en Roma.

\section{El alumno de la Academia de San Carlos}

José Gutiérrez llega a la Nueva España en 1787, alrededor de los 21 años, como alumno destacado de la Academia de San Fernando de Madrid, e inicia sus estudios en pintura en la Academia de San Carlos.

En 1788 se tienen noticias de él dentro de la Academia (22 años), cuando se une a una representación de varios pensionados el 19 de junio, quejándose por la actitud y deficiente enseñanza que recibían de los directores del plantel. En ese grupo de inconformes figuran también Tomás Suria, Gabriel Gil (hijo del director de dicha institución), Ignacio Sandoval, Luis de Martín Alonso, Juan Mariano Sandoval y José María Vázquez?. Parece que la queja no es sólo de los

6 Alberto Santoscoy, Obras completas, t. II, Guadalajara, Gobierno del Estado de Jalisco, 1984, pág. 107.

Archivo parroquial de la Notaría del Sagrario Metropolitano de Guadalajara, Jalisco.

Ibid, pág. 45.

9 Justino Fernández, Guía del Archivo de la Antigua Academia de San Carlos, 1781-1800, suplemento 3 del núm. 37 de los Anales del Instituto de Investigaciones Estéticas, México, 1968, gaveta III, núm. 283. 
alumnos, resulta que los directores de pintura y arquitectura también se manifiestan por el tratamiento áspero que les daba don Jerónimo Antonio Gil, director de la Academia, y solicitan a su vez al virrey que no se les obligue a asistir a la Academia durante el día, a lo que, después de varios oficios de ida y vuelta, el virrey Flores, el 18 de julio de ese mismo año, resuelve en acuerdo con la Junta de la Academia la asistencia de los directores durante el día y solicita se aperciba y reprenda a don Ginés Andrés de Aguirre y a don Cosme de Acuña, por desobedecer las órdenes de la Real Junta ${ }^{10}$.

De nueva cuenta Justino Fernández lo vuelve a encontrar en los expedientes del Archivo de San Carlos, cuando don Antonio González Velázquez, solicita a la Junta de la Academia el 29 de abril de 1790, que dos de sus discípulos más destacados, José Gutiérrez y Heredia le ayuden a ejecutar unos planos por estar éste mal de la vista desde su arribo a la Nueva España ${ }^{11}$. Y, a renglón seguido, en el expediente núm. 590, encontramos un oficio de los pensionados de pintura José Gutiérrez, José María Vázquez y Manuel García, pidiendo se les compren los cuadros donde han de pintar, pues sus pensiones no les alcanzan para ello. Ante esta solicitud cabe resaltar que hasta este momento Gutiérrez todavía se encuentra como pensionado de pinturas y será posteriormente cuando se cambie a arquitectura ${ }^{12}$. La situación económica de Gutiérrez era sumamente difícil ya que en la gaveta IV núm. 658, encontramos una solicitud de los jóvenes don Juan Sánchez y José Gutiérrez en donde requerían se les habilitase ropa para «cubrir sus vergüenzas». Posteriormente, obtiene un premio en sus estudios de geometría, lo que hace que se incline por la arquitectura, ramo al que decide cambiarse en 1791 y en el que obtiene una pensión ${ }^{13}$.

Al tiempo, lo volvemos a encontrar en la expedición de Alejandro Malaspina $^{14}$, realizada en 1791. Como es sabido, el siglo XVIII estuvo plagado por excursiones científicas - Cook, La Perouse, Bouganville, y las expediciones españolas a la Nueva España - lo que resume el espíritu del siglo. El 10 de septiembre de 1788, Malaspina escribe al ministro de Marina, Antonio Valdés, proponiéndole un viaje científico y político alrededor del mundo que implicaba dos objetivos:

\footnotetext{
10 Justino FERNÁNDEZ, gaveta III, documento 284 y 290, págs. 35-36.

11 Ibid., gaveta IV, núm. 589, pág. 66; consultar también Elizabeth Fuentes Rojas, La Academia de San Carlos y los constructores del Neoclasicismo, México, UNAM, 2002.

12 Ibid., gaveta IV, núm. 590, pág. 66.

13 Elizabeth Fuentes Rojas, op. cit., pág. 47.

14 Alejandro Malaspina (1754-1810) nació en Mulazzo, Italia, dentro del seno de una familia noble italiana. Ingresa en la Marina española en 1774 donde realiza una carrera exitosa, aunque a su regreso de sus expediciones es encarcelado y deportado a Italia.
} 
[...] el uno es la construcción de cartas hidrográficas para las regiones más remotas de América y de derroteros que puedan guiar con acierto la poca experta navegación mercantil; y la otra la investigación del estado político de las Américas, así relativamente a España como a las naciones extranjeras ${ }^{15}$.

Así, el 14 de octubre de 1788, se le notificaba a Malaspina, que había merecido la aceptación del rey el proyecto de dar la vuelta al mundo, a las corbetas Descubierta y Atrevida las cuales se hacían a la mar el 30 de julio de 1789, capitaneadas por Alejandro Malaspina y José Bustamante y Guerra ${ }^{16}$.

Los primeros estudios zoológicos realizados en la Nueva España corrieron a cargo del naturalista Antonio Pineda y Ramírez, quien estudió las especies marinas que habitaban las aguas profundas en la costa sur del virreinato, alrededor de Acapulco, quedando el dibujo de la numerosa flora novohispana descrita por los naturalistas a cargo de los pintores José Guío, Francisco Lindo y, excepcionalmente, José Gutiérrez ${ }^{17}$. Virginia González Claverán menciona que estos pintores hicieron las veces de los fotógrafos actuales, quienes captaron en una pequeña superficie de papel imágenes de personas, animales, objetos y paisajes, utilizando lo más avanzado en tecnología, como eran «dos cámaras ópticas portátiles», para facilitar la ejecución de perspectivas urbanas y de paisajes ${ }^{18}$.

En 1790 Malaspina se encuentra en Guayaquil, y Pozo, el pintor que lo acompañaba, abandona la expedición. Ante esta ausencia, Malaspina solicita dos pintores a España, pero al darse cuenta de que éstos no llegarán antes de la partida de las naves a Acapulco, le escribe al virrey de la Nueva España solicitándole ayuda. Este remite la solicitud al presidente de la Junta de la Academia, don Ramón de Posada, quien a su vez la envía al director, don Jerónimo Antonio Gil el 11 de enero de 1791. Ramón de Posada le solicita a Antonio Pineda19 que le permita a José Gutiérrez, junto con Tomás de Suria, acompañarlos en su excursión, pues, en su opinión,

\footnotetext{
15 Juan Pimentel Igea, Malaspina y la Ilustración, Madrid, Instituto de Historia y Cultura Naval, Ministerio de Defensa, 1989, pág. 18.

16 Ibid., pág. 19. Consultar The Malaspina expedition, in the pursuit of knowledge, con introdución de Richard Polese, Topeka, Kansas, USA, Museum of New Mexico Press, 1977.

17 Virginia González Claverán, Malaspina en Acapulco, Madrid, Instituto Guerrerense de Cultura, 1989, págs. 170-181.

18 Ibid., pág. 181.

19 Antonio Pineda, marino y botánico español, nació en Guatemala en 1753 y falleció en las Filipinas en 1792. Guardamarina reconocido por sus profundos conocimientos de las ciencias naturales, los que le permitieron ser designado, junto con Luis Née y Tadeo Haenke, para participar como encargado de las ciencias naturales en la Expedición Malaspina alrededor del mundo. Perdió su vida en el archipiélago filipino. Su hermano Arcadio, teniente de navío, fue el encargado de poner en orden sus apuntes, mientras el capitán Alejandro Malaspina, apenado por su pérdida, erigió un monumento a su subordinado en el Jardín Botánico de Manila.
} 
Gutiérrez, que era pensionado de arquitectura, apuntaba detalles de gran valía, por lo que debería cuidarse de su formación, ya que junto a Pineda tendría oportunidad de aprender nuevos conocimientos que fueran útiles para el ejercicio de la profesión ${ }^{20}$.

Comenta Carmen Sotos, que durante la excursión realizada por el interior de México, Gutiérrez y Francisco Lindo sustituyen a José Guío quien cae enfermo. Esta excursión se realiza durante tres meses donde Gutiérrez dibuja un total de veintiséis dibujos, quince eran vistas de poblaciones, ocho diseños de máquinas o instrumentos utilizados en el trabajo y el resto planos geográficos. Seis de estos planos se conservan en el Museo Naval de Madrid ${ }^{21}$.

Volvemos a saber de Gutiérrez en 1794 cuando alcanza el grado de académico de mérito con un proyecto de Palacio Real en estilo neoclásico, que en opinión de Carmen Sotos tiene una marcada influencia de su maestro Antonio González Velázquez, al concebir volúmenes muy alargados, en los que se marcan las líneas horizontales.

Al clasificar Justino Fernández la documentación del Archivo de San Carlos encuentra en la gaveta 8. 1794-1795 (números del 822 al 906), los siguientes documentos:

Gaveta 8. 1794-1795

827. José Gutiérrez y Juan Sánchez de la Real Academia, rama de arquitectura, solicitan que no se les quite la pensión que tenían asignada. Febrero 5 de 1794.

835. Don José Gutiérrez, pensionista del ramo de arquitectura, presenta planos y dibujos para que se le dé el título de Académico de Mérito, nombrándosele el 7 de julio de $1794^{22}$.

Por el documento 827 constatamos que tanto Gutiérrez como Sánchez recibían un apoyo económico por parte del gobierno de la Corona española para estudiar en San Carlos. Sin embargo en el libro de Jean Charlot, Mexican Art and the Academy of San Carlos 1785-191523, encontramos, que al referirse al programa de intercambio para realizar estancias fuera de México, hace el siguiente comentario por demás interesante:

20 Justino Fernández, op. cit., gaveta V, núm. 678, solicitud de Ramón Posada al conde de Revillagigedo, virrey de México, sobre la utilidad de que José Gutiérrez acompañe al teniente de guardias españolas, Antonio Pineda, en el viaje que está por hacer al Real de Guanajuato y otras partes, 21 de agosto de 1791.

21 A este respecto agradezco el apoyo del arquitecto Arturo Parra de Guanajuato, quien nos obsequió con una copia de la perspectiva que realiza Gutiérrez de Guanajuato.

22 Justino Fernández, op. cit., págs. 96 y ss.

23 Jean Charlot, Mexican Art and the Academy of San Carlos 1785-1915, Austin, University of Texas, 1962. 
The first offer of fellowships to Spain, made in 1793, had been met by a unanimous refusal from all six students selected, though under a variety of pretexts. Jose M. Guerrero and Jose M. Vasquez declined because they were married. Patiño and José Lopez refused to travel under the supervision of Don Cosme de Acuña. Jose Gutierrez and Joaquin Heredia feared the hazards of seafaring ${ }^{24}$.

Este comentario lo toma Jean Charlot, de las Obras de Revilla de una carta del virrey Revilla Gigedo (sic) a don Antonio Porlier, donde se explica el porqué de este rechazo unánime a viajar hacia España:

A letter from Viceroy Revilla Gigedo to Don Antonio Porlier most likely comes close to the subconscious reason behind these refusal when it status that, though the advanced students doubtless should go to Spain to complete their studies, an obstacle would be that "owing to an exaggerated love of their Fatherland (Mexico) and its people, the natives prefer their own ways, even those who go about in the raw ${ }^{25}$.

Ante este comentario nos surgen un par de dudas: ¿Por qué se refieren a Gutiérrez como nativo de México cuando sabemos que era español? ¿Por qué Gutiérrez no aprovecha esta oportunidad para regresar a España y estar con su familia después de siete años de separación?

Al respecto Gutiérrez siempre se vanaglorió de su calidad de español peninsular, y eso lo comprobamos por su participación en contra de la guerra de Independencia, donde se enlista en las fuerzas realistas. Y, respecto a no querer regresar a España, habla de un desapego hacia sus raíces y su enclave familiar, que demuestra una contradicción en su personalidad, por lo que explicaría su exigencia de recibir la mejor enseñanza para contar con herramientas que le permitieran abrirse camino en un país desconocido y sin un «padrino»que le abriera las puertas.

A los 22 años de edad recibe Gutiérrez su título de académico de mérito de arquitectura y con ello el reconocimiento de González Velázquez, director de arquitectura y de Constanzó, director de matemáticas, quienes complacidos solicitan que los apoye: el primero en sus cursos y el segundo en sus proyectos de construcción ${ }^{26}$.

Ya siendo Gutiérrez académico de mérito de San Carlos, inicia su práctica profesional, y solicita se le conceda una hora por las mañanas para asistir a la

\footnotetext{
24 Jean Charlot, op. cit., pág. 38.

25 Ibid., pág. 38.

26 Elizabeth Fuentes, op. cit., pág. 47.
} 
construcción de la Fábrica de Tabacos como ayudante del director don Miguel Constanzó, en julio 31 de 1795. El primer proyecto para su construcción fue realizado por don Manuel Agustín Mascaró, el cual fue rechazado por la Real Academia de San Fernando el 6 de mayo de 1792, asignándole la realización del nuevo proyecto a don Antonio González Velázquez, director de la academia de arquitectura ${ }^{27}$.

Posteriormente, el 20 de enero de 1797, Silvestre Díaz de la Vega le comunica a Gutiérrez la orden del excelentísimo virrey para que cuidara la dirección de la fábrica de tabaco, durante la ausencia del coronel de ingenieros don Miguel Constanzó, y del director de arquitectura, a lo que Gutiérrez respondió se le indicara en qué consistían sus funciones, respondiéndole Silvestre Díaz de la Vega, el 1 de febrero de 1797, mediante un oficio que dice: «Como inteligente cuide de la conservación de lo fabricado por medio del riego, para cuyo fin se destinan seis peones». Sin embargo, para el 20 de ese mismo mes, al regreso a la capital de González Velázquez y de Miguel Constanzó, se le cesaba del encargo de la dirección y cuidado de la obra. González Velázquez, le solicita, por estar muy ocupado en las obras del camino de Veracruz, de la Real Casa de Moneda y Apartado y en la dirección de la Academia, que se quede con el encargo de vigilar la obra de la fábrica de cigarros, yendo dos veces por semana y dándole aviso de cualquier novedad (febrero 22 de 1797). A este edificio se le conoció posteriormente como el de la Ciudadela y es donde actualmente se encuentra la Escuela de Artesanías de la Ciudadela, localizada frente a la plaza de la Ciudadela, al este la calle de Balderas, al sur la de Tolsá, y al oeste la de Enrico Martínez.

Como se puede observar, el año de 1797 fue especialmente importante para Gutiérrez por los proyectos que se le solicitan realizar. En marzo se le encargan las obras de las garitas altas y del caso de esta ciudad, solicitando el arquitecto que para llenar esta comisión se le concedan dos días naturales en cada semana. Este nombramiento le fue ratificado por el secretario de la Junta de Rentas y Resguardos, Lic. José María Arce y Echegaray en abril 22 de 1797, sustituyendo a don Miguel Constanzóo ${ }^{28}$.

$\mathrm{Al}$ año siguiente, en octubre 2 de 1798, encontramos a Gutiérrez solicitando licencia para curarse, acompañando certificado dado por don José Carmona, y el 1 de junio de 1799, Gutiérrez envía un oficio sobre el asunto del sueldo, debido a que sólo recibía de la Academia $\$ 400.00$ pesos anuales y tenía que sostener a su familia, por lo que suponemos que ya estaba casado ${ }^{29}$. Desgraciadamente en

\footnotetext{
${ }_{27}$ Sonia Lombardo de RuIz, La ciudadela, ideología y estilo en la arquitectura del siglo XVIII, México, UNAM, 1980, págs. 44-45.

${ }_{28}$ Ibid., gaveta 9, núm. 935937, pág. 106.

29 Elizabeth Fuentes, op. cit., pág. 47.
} 
este mismo año encontramos un dato muy relevante y extraño. En abril de 1799, Gutiérrez solicita que la Junta de Policía le devuelva su título, detenido por espacio de catorce meses, y se abstenga de mandarlo a la Junta de Gremios. ¿Qué pasó aquí? Parece ser que, inmediatamente después de que se le encargan las obras de las garitas alta y baja de la ciudad de México, le quitan su título, por lo que nos preguntamos ¿qué hizo el arquitecto para merecer semejante sanción? La respuesta la encontramos en el libro de Elizabeth Fuentes donde menciona que precisamente en 1799 Gutiérrez tiene un problema con la fiscalía debido a unos planos que realiza sobre el Colegio Apostólico de Orizaba, planos que González aprueba y que los fiscales no autorizan y piden se rectifiquen. Esta situación ofende gravemente a su maestro, quien defiende a su discípulo diciendo:

[...] son los más celosos defensores [...] del bien público [...] y la buena inversión de caudales de fábricas [...] [pide] se les guarden y cumplan como S. M. quiere en recompensa del penoso trabajo, su estudiosa y larga fatiga en metodizarse en su profesión [...] y exige que a los otros maestros de obra se les hagan correcciones, pero no a él que hizo sus estudios en la Real Academia de San Fernando y director de San Carlos y por lo tanto [...] calificador primero de todas las obras del Reyno [...] (sic) $)^{30}$.

Este señalamiento y la actitud agresiva y ofensiva de su maestro provoca que se le retire su título por espacio de catorce meses. Esto le causó a Gutiérrez un gran resentimiento y así lo constatamos cuando solicita en 1813 la plaza de director de arquitectura, y sabiendo que su maestro ya había fallecido su apoderado realiza la siguiente queja en relación del tiempo en que trabajó para Velázquez diciendo:

[...] ocupado en las infinitas ocurrencias del manejo de una Academia tan vasta, teniendo que llevar las faltas del director y atendiendo a sus particulares deberes [...] así como [...] al sólido mérito que se han granjeado sus servicios en más de veinte años de continuas tareas en la Real Academia [...] se puede argüir con certeza [...] que Gutiérrez es [...] el sujeto más benemérito que tiene la Real Academia [... $]^{31}$.

Volvemos a notar en Gutiérrez muchas contradicciones, por un lado, tener que aceptar las situaciones vergonzantes que le hacían pasar sus maestros, la humillación de que se le quitara su título por causa de su maestro Velázquez, y por otro lado, ya como académico de mérito de arquitectura en San Carlos, la rigidez

$30 \quad$ Ibid., pág. 47.

31 Ibid., pág. 48. 
académica que él mismo se exigía en cuanto a su desempeño, aparte del «estatus» que provocaba en sus pupilos el ser egresados de una institución de tanto prestigio. Estos académicos, define Elizabeth Fuentes, desempeñan el papel de reformadores, instructores y árbitros de la construcción y capitalizan el esfuerzo de romper con las ataduras del barroco y abordar las nuevas formas clásicas de la cultura decimonónica para dar paso al progreso y al racionalismo de la mentalidad ilustrada ${ }^{32}$.

\section{El arquitecto en Guadalajara}

La monarquía ilustrada de Carlos III apostó por una revolución cultural al fomentar el estudio de los idiomas, el dibujo, la pintura, los textiles y tapices, las ciencias naturales, la geografía y las ciencias exactas ${ }^{33}$. Guadalajara, sumándose a esa intención, creó la Escuela de Dibujo la cual funcionó de 1790 a 1810, en su primera etapa y de diciembre de 1816 a mayo de 1818, fecha en que se clausura definitivamente $^{34}$. En sus primeros seis años de vida la escuela se ubicaba en un salón del extinto Colegio de Santo Tomás. Al instalarse en 1792 la Universidad, comenta Arturo Camacho, a solicitud del síndico procurador, el señor rector cedió «una espaciosa y cómoda sala en el costado del edificio», para posteriormente cambiarse a las oficinas del Real Consulado ubicadas en la manzana norte de lo que actualmente es la rotonda de los Hombres Ilustres. El 20 de junio de 1805, el rey aprobó el establecimiento de una Academia de Dibujo en el Real Consulado, y fungió José Gutiérrez como docente en esa Academia, según consta en el contrato de trabajo que firma ante el obispo Cabañas. En este establecimiento se impartían las clases de aritmética, geometría y arquitectura. Cabañas apoyaba a la institución con el pago de los honorarios de Gutiérrez, y además cubría «los gastos necesarios para mesas, asientos, candiles, papel, lapiceros y todos los demás utensilios precisos $»^{35}$. Posteriormente el Real Tribunal del Consulado asumió su mantenimiento a partir del 1 de junio de 1808, gastando en el mismo la cantidad de $\$ 4,489.00$ pesos distribuidos en salarios, materiales y premios de los alumnos hasta su cierre en 1810, con motivo de la guerra de la Independencia ${ }^{36}$.

$32 \quad$ Ibid., pág. 32.

33 Arturo Cамасно, Álbum del tiempo perdido, pintura jalisciense del siglo XIX, Colección de Artes y de Letras, Guadalajara, El Colegio de Jalisco, 1997, pág. 61.

34 Luis M. RiverA, «La Instrucción pública primaria en Guadalajara Colonial», en Gaceta Municipal, Guadalajara, t. IV, núm. 9, 15 de octubre de 1920, pág. 6, citado en Arturo Caмaсно, op. cit., pág. 61.

${ }_{35}$ Archivo Eclesiástico del Arzobispado de Guadalajara, Cuaderno del Colegio Clerical, 1805, citado en Arturo, ibid., pág. 62.

36 José Ramírez Flores, El Real Consulado de Guadalajara, Guadalajara, Banco Refaccionario de Jalisco, 1952, pág. 77, citado en Arturo Самасно, op. cit., pág. 62. 
El obispo Juan Ruiz de Cabañas y Crespo solicita al arquitecto Tolsá la realización del proyecto de la Casa de la Misericordia, y éste por sus múltiples ocupaciones delega esta responsabilidad a José Gutiérrez; esta aseveración la constatan los historiadores de la época, Santoscoy, Pérez Verdía, y actualmente Toussaint, Arturo Camacho y Elizabeth Fuentes. En la Academia de San Carlos no se encuentran registrados los planos o dibujos de la Casa de la Misericordia. Tampoco se tiene conocimiento de la solicitud de Tolsá para ausentarse con motivo de la dirección de la Casa de la Misericordia. Sabemos que el arquitecto-maestro debía encontrarse agobiado con la fundición de la estatua del «Caballito», construyendo el Palacio de Minería y la casa de Francisco Fagoaga, márques del Apartado; también por esta época (1803) terminaba el palacio del conde de Buenavista, e inicia la construcción del ciprés de la catedral de Puebla; por lo que es casi imposible argumentar que Tolsá tuviera el tiempo y la calma para proyectar una Casa de la Misericordia que no le traería fama ni fortuna, a las que estaba acostumbrado, en la ciudad de México. Más bien es de suponer que le debió de solicitar este encargo al académico José María Gutiérrez López, recomendándolo ante el obispo Cabañas para que fuera el constructor.

Sumado a lo anterior surge la siguiente pregunta: ¿por qué existe un retrato al óleo de Cabañas atribuido a Felipe Castro, pintor jalisciense, realizado pocos años después de la muerte del obispo, donde aparece con un plano desplegado en la mano derecha con la inscripción: «plano y proyecto de Josep Gutiérrez»? Esta pintura es de autor anónimo pero se supone fue realizada unos treinta o cuarenta años después de la muerte del obispo (1824), por lo que quien realizó el mencionado cuadro tendría la posibilidad de tener la información de primera mano. En el espacio donde se encuentra colgado el mencionado cuadro, en el salón noroeste del patio de los Naranjos, se encuentra pintada en uno de sus muros la cronología de la Casa de la Misericordia, actualmente Hospicio Cabañas, donde se menciona:

1803- El proyecto conocido como Casa de la Misericordia fue aprobado el día 5 de diciembre y erigido en la casa, huerta y solar de El Sabino, terreno donado por Pedro Díaz de Escandón, quien lo había adquirido a nombre del Obispo Cabañas.

1805- Bajo el diseño del arquitecto Manuel Tolsá, con la dirección de su alarife José Gutiérrez, da inicio la construcción de la Casa de la Misericordia. Se contó con la ayuda de 300 operarios quienes continuaron trabajando activamente hasta 1809.

Definitivamente existe un error al mencionar que Gutiérrez fue alarife de Tolsá, cuando sabemos que primeramente consigue éste su título en 1794 y Tolsá lo solicita hasta 1796, cuando realiza los planos para el Palacio de Minería en 
la ciudad de México y los planos de unas celdas para el convento de Regina (las de la marquesa de Selva Nevada) y el diseño de un retablo. También es de notar que se suspende la obra de la Casa de la Misericordia hasta 1810, con el inicio del movimiento independentista. Por lo que, cumpliendo con uno de los objetivos de esta investigación, se solicitará a los directivos del Hospicio Cabañas modifiquen esta información.

Martín Rafael de Bachelena, celebra en la ciudad de México, el 8 de febrero de 1805 y en representación del obispo Cabañas, el contrato con José Gutiérrez. En ese acuerdo se menciona la obligación de Gutiérrez de residir en Guadalajara por lo menos 4 años, dando clases por la mañana o por la noche de dibujo, aritmética y geometría, recibiendo una remuneración de $\$ 1000.00$ anuales. De igual manera se obliga a Gutiérrez a dirigir en calidad de maestro arquitecto el edificio de la Casa de la Misericordia, con arreglo al plan formado por don Manuel Tolsá, recibiendo por ello $\$ 300.00$ anuales. Además recibirá $\$ 400.00$ para gastos de viaje y transporte a Guadalajara. De la misma manera el señor obispo intercederá para que se le encomiende la obra del templo del Sagrario, cuyo plano fue realizado por el mismo Gutiérrez y aprobado por la Real Academia ${ }^{37}$.

Para trasladarse a Guadalajara, Gutiérrez utiliza el servicio de coches, el cual se había instituido a partir del 1 de marzo de 1794, y que costaba $\$ 62.50$ el asiento. Éste salía a principios del mes de la ciudad de México y tardaba 12 días el recorrido, pasando por Querétaro, Irapuato, la Venta de los Horcones, León, Lagos, Zapotlanejo, Tlaquepaque hasta llegar a Guadalajara ${ }^{38}$.

$\mathrm{Al}$ instalarse en Guadalajara, Gutiérrez, como el flamante arquitecto egresado de la Academia de San Carlos, debía presentarse acorde a la categoría que esto le obligaba ${ }^{39}$. Inicia cuanto antes el trazo de la cimentación de la Casa de la Misericordia para evitar que se le viniera encima lo que los indios llamaban «jopantla», que era el temporal de lluvia que se iniciaba «por San Juan», para terminar a principios de octubre "por San Francisco». Eran tan fuertes los temporales de lluvia acompañados por truenos y rayos que los tapatíos de aquella época invocaban a toda la corte celestial, en especial a San Clemente, a San José, por ser el «abogado intercesor contra las tempestades, truenos y rayos y piedras

37 Ramón Mata Torres, Los que construyeron el Cabañas, Guadalajara, Ediciones Kauyumari, 1996, pág. 26.

38 Leopoldo Orendain, en José María Murí́ y Jaime Olveda, Sociedad y costumbres, lecturas históricas de Guadalajara, t. II, Guadalajara, INAH, UDG, 1991, pág. 323.

39 En aquella época los miembros de la sociedad alta vestían con un rompe coche de pana o de Holanda, y reservaban para las fiestas la casaca o chupa de seda, chupín o chaleco largo y calzón corto. Siempre vestían medias de seda, con zapato bajo con hebilla primorosamente cincelada, manufacturadas en Filipinas. El cabello su usaba corto y peinado hacia adelante sobre la frente en forma de fleco recortado, cubriéndose la cabeza con un enorme sombrero negro llamado «empanada», por la figura que tenía. En Luis Pérez VerdíA, op. cit., pág. 4. 


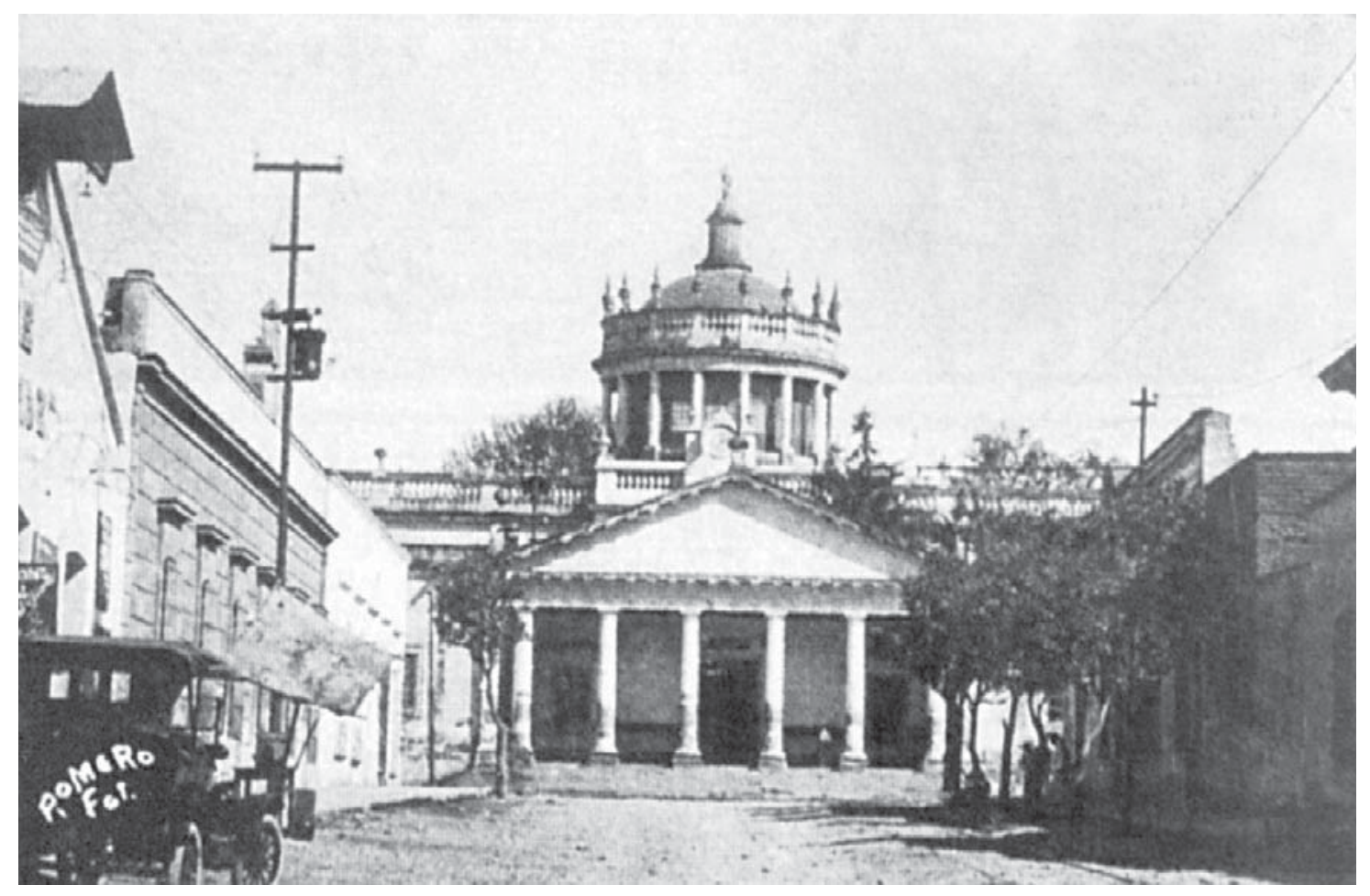

La Casa de la Misericordia

con que esta tierra es molestada», aparte de las jaculatorias que se rezaban constantemente a «Santa Bárbara Doncella líbranos de un rayo y de una centella» y a «San Isidro Labrador, quita el agua y pon el sol» ${ }^{40}$.

Al igual que los tapatíos, Gutiérrez también leía las publicaciones periódicas que llegaban a Guadalajara: la Gazeta de México (sic) y la Gazeta de Madrid (sic), los comerciantes del Real Consulado leían el Semanario de Agricultura y Artes, y también se recibían dos periódicos españoles en Guadalajara entre 1808 y 1811: el Correo Político y Literario de Salamanca y el Semanario Patriótico ${ }^{41}$, estos últimos en franco apoyo a la independencia en España.

También en 1808, Gutiérrez apoyaba y asistía a las corridas de toros que se celebraban con el propósito de hacerse de fondos el ayuntamiento para la remodelación del barrio de San Juan de Dios, escondrijo de jugadores, ladrones e individuos de oficio sospechoso y «limpiar de mala gente aquel barrio» debido a la construcción de la Casa de la Misericordia que se estaba construyendo en ese

\footnotetext{
40 Luis René Navarro, en José María Muria y Jaime Olveda, Sociedad y costumbres, lecturas históricas de Guadalajara II, Guadalajara, INAH, UDG, 1991, t. I, págs. 231-235.

${ }^{41}$ Carmen Castañeda, Imprenta, impresores y periódicos en Guadalajara 1793-1811, Guadalajara, Editorial Ágata, 1999, pág. 95.
} 


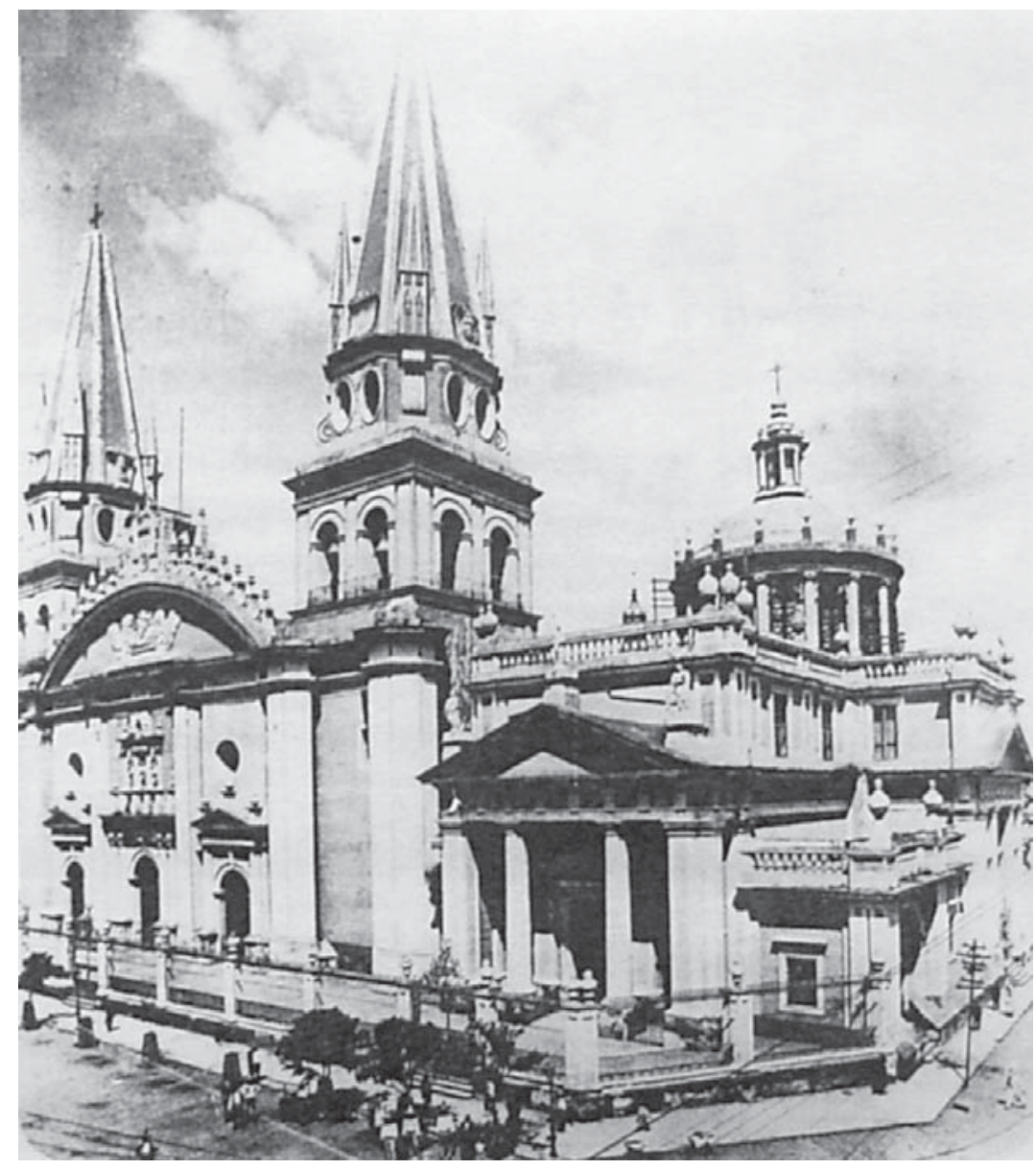

Templo del Sagrario

barrio. El producto de estas corridas serviría para empedrar calles ${ }^{42}$, situación que beneficiaba a Gutiérrez para la mejor comunicación vial con la construcción que estaba dirigiendo.

En ese momento se le solicita el proyecto y elaboración del Puente Verde que se encontraba frente al nacimiento de las calles de Catalán y de Borregos, e inicia la construcción del templo del Sagrario, la cual quedo interrumpida cuando sus muros estaban a más de 5 metros de altura por la guerra de Independencia $(1810)^{43}$.

De igual manera los españoles avecindados, al igual que José Gutiérrez, leían el Correo Político y Literario Español, el cual se publicaba dos veces por semana, en formato de a cuarto, y donde se publicaban las «proclamas a las

42 José María Muria y Jaime Olveda, Sociedad y costumbres, lecturas históricas de Guadalajara, tomo II, Guadalajara, INAH, UDG, 1991, t. I, págs. 231-235, pág. 235.

43 Ramón Mata Torres, op. cit., pág. 27. 
provincias y ciudades de España, dirigida desde Murcia el 22 de junio a los andaluces después de la rendición del ejército francés en las faldas de la Sierra Morena» ${ }^{44}$. También en este periódico se reprodujo la «receta para hacer Napoleones» que decía:

Las recetas para hacer franceses, para hacer Napoleones, o para deshacerlos proliferan en los periódicos de las ciudades no ocupadas, que se los pasaban con rapidez. Pondré un solo ejemplo: el 29 de agosto de 1808 el Diario de Badajoz publicaba una Receta para hacer Napoleones y es infalible, que insertaba el día 30 el Diario de Valencia, tomándola, según confesaba, del Diario de Santiago; también la encontramos en el Correo Político y Literario de Salamanca, y sería recogida más adelante en la Colección erudita, tanto en prosa como en verso, agradable y curiosa, no menos útil que gustosamente entretenida. Arte de vivir alegre y reírse de Napoleón Bonaparte, impresa en Jerez de la Frontera ${ }^{45}$.

La receta para hacer Napoleones, y es infalible

Soneto

Coge un puño de tierra corrompida, un quintal de mentira refinada, un barril de impiedad alambicada y una azumbre de audacia bien medida.

La cola del pavón, coge extendida; del tigre, la uña ensangrentada; del corzo el corazón, y la taimada cabeza de la zorra envejecida.

Todo esto, bien cosido en un talego de exterior halagüeño, hermoso y balndo (sic), arrimaras de la ambición al fuego.

Déjalo que se vaya incorporando, y tú verás sin duda como luego sale un Napoleón de allí volando ${ }^{46}$.

44 Manuel Gómez Imaz, Periódicos durante la guerra de Independencia (1808-1814), Madrid, Tipográfica de la Revista de Archivos, Bibliotecas y Museos, 1910, pág. 83, citado en Carmen Castañeda, op. cit., pág. 100.

Correo Político y Literario de Salamanca, núm. 17, martes 2 de agosto, 1808, págs. 121-128.

45 Sobre estas recetas véase Ana María Freire LóPEz, "La literatura española en 1808», Revista de Historia Militar, núm. extraordinario 2 dedicado a «Entre el Dos de Mayo y Napoleón en Chamartín: los avatares de la guerra peninsular y la intervención británica», 2005, págs. 267-284.

46 Manuel Gómez Imaz, Periódicos durante la guerra de Independencia (1808-1814), Madrid, Tipográfica de la Revista de Archivos, Bibliotecas y Museos, 1910, pág. 83, citado en Carmen Castañeda, op.cit., pág. 102. 
Inicia el movimiento de la Independencia el 15 de septiembre de 1810, comandado por Hidalgo quien llega a Guadalajara el 12 de diciembre, y se apoderó de los caudales públicos logrando recaudar cerca de $\$ 500,000.00$ con lo que apenas si pudo pagarle a la chusma numerosa que él llamaba ejército ${ }^{47}$. El 13 de diciembre comenzó la terrible matanza de españoles; éstos se hallaban presos en el edificio del Seminario, (hoy Museo Regional de Guadalajara) y en el Colegio de San Juan, custodiados por numerosa tropa comandada por Agustín Marroquín, bandolero apresado y encarcelado a fines de 1805, y puesto en libertad a la llegada de Hidalgo ${ }^{48}$. En partidas de 20 a 30 españoles los sacaban a media noche y los degollaban, unos en las barranquitas de Belén y otros en el cerro de San Martín. Treinta días duró este horror: del 13 de diciembre al 13 de enero, donde se calcula ejecutaron a más de 300 españoles. El capitán don José Pérez de Acal logró salvar a 64. Revisando las listas de los españoles salvados no encontramos el nombre de Gutiérrez por lo que suponemos que él no se encontraba ya en la ciudad. En este momento me detengo para puntualizar una circunstancia importante; a la llegada de Gutiérrez a Guadalajara, éste inicia una relación muy cordial con el obispo Cabañas quien aprovecha los conocimientos de Gutiérrez para solicitarle varios trabajos extras, como lo fue el proyecto que realiza el arquitecto para el convento-colegio de la enseñanza de la Compañía de María, en Aguascalientes. Éste elabora dos: uno grande, con bajos solamente; el otro más pequeño de dos pisos $^{49}$. Se le paga la cantidad de $\$ 1,000.00$ pesos según consta en el testamento de doña María Porfiria Dávalos, quien apoyó con recursos económicos para la fundación y construcción del convento-escuela, aunque también menciona lo siguiente:

[...] mil pesos que dio al Alarife José Gutiérrez, por el mapa que hizo para la construcción del convento y mil treinta y nueve pesos tres reales que quedaron en su poder de los que no dio descargo ${ }^{50}$.

Finalmente este convento no se construyó utilizándose una casa como convento provisional y que fue donada a las monjas por Mariano Guerrero.

47 Luis Pérez Verdía, op. cit., pág. 63.

48 José Ramírez Flores, El gobierno insurgente en Guadalajara, 1810-1811, Guadalajara, Publicaciones Ayuntamiento de Guadalajara, 1969, pág. 33.

49 Pilar Foz y Foz, La revolución pedagógica en la Nueva España: 1754-1820, t. I, Madrid, Publicación del Instituto de Estudios y Documentos Históricos, A.C. 1981, pág. 404.

50 Op. cit., t. II, pág. 183. 


\section{El revolucionario}

Al estallar la guerra de la Independencia en 1810, Gutiérrez se alistó en las tropas reales a las órdenes de don Félix María Calleja donde sirvió como ingeniero en la Real Artillería y en el Ejército del Centro. Participó en la batalla del Puente de Calderón, en las de Zitácuaro y Cuautla para posteriormente integrarse en la ciudad de México a la compañía «Defensores de la integridad del Imperio Español», donde su maestro Miguel Constanzó fue el jefe del Cuerpo de Patriotas Nobles $^{51}$. Se le nombra director de la obra material de la fábrica de barrenos de fusiles en Chapultepec. Afincado de nueva cuenta en la ciudad de México, solicita ante la Academia el puesto de director de arquitectura, haciendo mención a las proezas realizadas durante el movimiento bélico, informando que estuvo en la batalla y derrota del cura Tapia, verificada el 16 de marzo; que tuvo a su vez el cuidado de los cañones que conducía el convoy que iba y venía a México durante el sitio de Cuautla, además de servir como artillero y guardaparque (sic). Además continúa relatando que como arquitecto realizó todas las obras necesarias en el Real Cuerpo de Artillería, tanto en la ampliación del cuartel, como en la formación de planos, reconocimientos, avalúos, pareceres, etc., sin recibir gratificación alguna, por haber cedido a favor de su majestad, en esa última época, el sueldo que le correspondía como voluntario y encargado de la artillería. Hace hincapié en el hecho de que durante el tiempo de campaña, no obstante su carácter como ingeniero y artillero, solamente recibió $\$ 22.00$ mensuales $^{52}$. Al abandonar Guadalajara, sus bienes le fueron confiscados ${ }^{53}$.

Tras este terrible descalabro, Gutiérrez, instalado en la ciudad de México y después de mucho insistir es nombrado director de arquitectura en 1813 de la Academia de San Carlos, con la condición de aceptar compartir su sueldo con el maestro Tolsá, por lo que se le designó la cantidad de \$1000.00 anuales y los otros \$1000.00 se le entregarían a Tolsá a título de jubilación. A la muerte de éste, reclama la dotación completa al rey, justificando este aumento por los 18 meses que había tenido que soportar sin sueldo, viviendo a expensas de amistades, cargado de deudas, enajenando a muy bajo precio sus libros, instrumentos y muebles y embargado su sueldo de director, sin dejar por eso de asistir al cumplimiento del deber en la Academia, autorizándosele solamente la cantidad de $\$ 1,250.00$ anuales, honorarios que correspondía para los residentes

\footnotetext{
51 Carmen Sotos Serrano, Los pintores de la expedición de Alejandro Malaspina, Real Academia de la Historia, 1982, pág. 154.

52 Federico E. Mariscal, Dos arquitectos en la guerra de la Independencia Mexicana, México D.F., Sociedad Mexicana de Geografía y Estadística, 1938, pág. 515.

53 Carmen Sotos Serrano, op. cit., pág. 154.
} 
americanos ya que no se le consideraba como director español, para quienes les correspondía un sueldo de $\$ 2,000$ pesos.

Inicia sus labores como director, y comete los mismos errores que sus antecesores, ya que encontramos un expediente en 1819, relativo a un dictamen negativo que emite junto con Manuel Castro, acerca de unos planos de la torre de la parroquia de Veracruz, realizados por Manuel López Bueno, quien ofendido ante los señalamientos emitidos, arma un alboroto, quejándose ante la Junta y ofendiendo a los directores. Ante este hecho, Gutiérrez se defiende y aprovecha también para quejarse por el hecho de que le solicitaran dictaminar junto con Castro, cuando a su juicio: «no era un arquitecto capacitado ni aprobado en su profesión». Finalmente para evitar más conflictos la Junta decide que se aprueben los planos.

Esta situación provoca que de nueva cuenta surja el conflicto de tener que dictaminar una obra en conjunto los directores de arquitectura y de matemáticas, y ante las quejas de Gutiérrez, el presidente de la Academia, le escribe al virrey para demostrarle lo infundado de las quejas del arquitecto diciendo que era:

[...] genio duro y cosquilludo (sic) [...] [quien] contra toda razón y desoyendo mil consejos [...], ignora que es beneficioso que para revisar los planos la Academia se recurra a más personas $[\ldots]$ ya que más ven cuatro que $\operatorname{dos}^{54}$.

Ante esta amonestación Gutiérrez demanda, en agosto de ese mismo año —1819 — a la Academia, y ésta se niega a comparecer ante las autoridades por tratarse de un asunto de insubordinación y no de un asunto contencioso; insiste el arquitecto ante el alcalde primero constitucional y es cuando la Junta indignada ante la insubordinación y caprichos de Gutiérrez, le advierte: «que si no se aquieta en el particular y varía sus procederes [...] procederá de inmediato e irremisiblemente a removerlo de la plaza de director [...]». La situación económica de Gutiérrez era muy difícil ya que desde 1820, la Academia empieza a suspender el pago de los sueldos a los directores, y como consecuencia, tres años antes le habían embargado todos sus bienes por el atraso del pago de arrendamiento de la casa que habitaba. Como podemos advertir en este momento de su vida, a los 61 años de edad, Gutiérrez no ha logrado consolidar una posición económica, y su relación profesional y académica ante la Academia está sumamente resquebrajada, por lo que acepta gustosamente el ofrecimiento de trasladarse de nueva cuenta a Guadalajara, en 1827, como profesor del Instituto de Ciencias del Estado de Jalisco.

54 Elizabeth Fuentes, op. cit., pág. 48. 
Pasado el movimiento revolucionario de la independencia, el país inicia una tensa calma, con infinidad de problemas que afrontar. Entre los más era obtener el reconocimiento de su independencia por los países europeos y en especial de España, reestructurar la economía, garantizar un ambiente propicio que facilitara la estabilidad en la agricultura, la minería y la industria; aparte de todo esto imperaba la desorganización social en el país, así como el deseo de autonomía de las provincias, donde Jalisco no era la excepción ${ }^{55}$.

El partido liberal pone en marcha las ideas surgidas en Francia e Inglaterra que tenían como objetivo la igualdad del hombre ante la ley; establecer como forma de gobierno el federalismo, llevar a cabo la secularización; la protección de los derechos de propiedad y libertad económica y establecer un sistema de educación nacionalizado claramente secular ${ }^{56}$.

En lo relativo a la educación, el control y planteamiento de la educación elemental recae en los intelectuales, quienes toman como modelo y guía el sistema de enseñanza mutua, que tenía como objeto: «formar una raza nueva de hombres cuyos sentimientos individuales los identifiquen con la independencia y la libertad $»^{57}$. Al aceptarse el sistema federal se especificó que cada Estado promovería la enseñanza dentro de sus límites.

Estas nuevas ideas van integrándose en la mente de los nuevos caudillos y dirigentes; sin embargo, las costumbres y tradiciones de la sociedad se mantienen intactas y así, tras del movimiento de la Independencia y posteriormente la ocupación del Ejército Trigarante en México, el conjunto de la sociedad en la Nueva Galicia se apresta a festejar este acontecimiento con bomba y platillo. Se instaló en palacio la noche del 22 de septiembre de 1821 la Junta Patriótica de Nueva Galicia, destinada a promover el adelanto de la Ilustración, de las artes, de la agricultura y de la moral pública donde el obispo Cabañas, ya de regreso a su diócesis, pronuncia un discurso encomiando la educación de la juventud al progreso social; la necesidad del fomento de la agricultura y del comercio como fuentes de la riqueza pública y cultivo de las artes en las sociedades organizadas ${ }^{58}$.

El 24 de enero de 1825 tomó posesión como gobernador constitucional del Estado de Jalisco el Excmo. D. Prisciliano Sánchez. Al día siguiente las autoridades, altos servidores públicos y académicos le presentaron sus respetos, vistiendo

\footnotetext{
55 Daniel Cosío Villegas, Historia General de México, t. III, México, El Colegio de México, 1977, págs. 10-13.

56 Charles Hale, El liberalismo en la época de Mora, 1821-1854, México, Ed. Siglo XXI, 1978, pág. 42.

57 Ibid., págs. 173-174.

58 Luis Pérez Verdía, op. cit., pág. 240.
} 
todos casaca con chaleco, calzón corto y medias de seda negra, corbata blanca y zapatos con hebilla de oro ${ }^{59}$. Una de las primeras acciones realizadas, fue la de mandar formar un censo donde se reconoce que en Guadalajara existían 47,125 hombres, 52,267 mujeres dando una población de 99,392 habitantes ${ }^{60}$.

Prisciliano Sánchez invirtió gran parte del presupuesto del estado en la educación y así lo aseveraba al decir:

La educación pública es a manera del sol resplandeciente que ilumina, vivifica, anima y conserva el ser de la sociedad [...] un pueblo sin ilustración es juguete de sus mandarines, víctima de su ambición, ludibrio de las vicisitudes del tiempo y presa de las ilusiones supersticiosas ${ }^{61}$.

El 16 de enero de 1826, suprimió los establecimientos de la Universidad y del Colegio de San Juan, diciendo que:

Con esta medida tomada por el gobierno no atacaba a «la libertad y a las letras», con ella desaparecía lo inútil e ineficaz, para sustituirlo ventajosamente con una fuente de ciencia más pura y abundante ${ }^{62}$.

De igual manera comenta Laura Edith Domínguez, que estas medidas eran acordes al nuevo sistema de enseñanza individual libre y gratuita, donde el acceso a la educación sería para todo aquel que tuviera el deseo de gozar de tal beneficio. Para tal motivo el Congreso aprobó el 29 de marzo de 1826 la Ley de Instrucción Pública dividida en cuatro clases: la primaria en las escuelas municipales, la secundaria que incluía el dibujo y la geometría en la cabecera de departamento, la tercera que abrazaba las matemáticas en los cantones y la profesional exclusiva del Instituto de Ciencias en la capital ${ }^{63}$.

Este nuevo plantel —comenta Pérez Verdía-constaba de once secciones: matemáticas puras; gramática general, castellana, francesa e inglesa; lógica, retórica, física y geografía; química y mineralogía; botánica; derecho natural, político y civil; economía política, estadística e historia americana; moral, instituciones eclesiásticas, historia y concilios; anatomía descriptiva, anatomía patológica y cirugía; instituciones médicas, clínica y medicina legal; y academia de dibujo,

59 Luis Pérez Verdía, op. cit., pág. 303.

${ }^{60}$ Op. cit., pág. 305.

${ }^{61}$ Ibid., pág. 306.

62 Laura Edith Domínguez González, El Instituto de Ciencias del Estado de Jalisco, Guadalajara, UNED, Gobierno del Estado, 1987, pág. 21.

63 Luis Pérez Verdía, op. cit., pág. 307. 
escultura y pintura ${ }^{64}$. Para las clases de dibujo, escultura y pintura se contrata a José Gutiérrez. Este Instituto no inicia sus labores hasta al año siguiente (1827) debido a que las reparaciones del edificio contiguo al templo de Santo Tomás donde anteriormente se encontraba la Universidad ya que no satisfacía las exigencias de la enseñanza moderna ${ }^{65}$.

El Instituto

fue el más feliz y perfecto que por entonces se hizo, no sólo para despejar de todos sus vicios la educación y la enseñanza, sino para introducir los nuevos métodos que facilitaran la una y la otra en los países más adelantados en la civilización ${ }^{66}$.

Se destinaron para su funcionamiento los fondos que pertenecían a la Universidad y al Colegio de San Juan, y un impuesto creado especialmente para la instrucción pública denominado «fondo provincial», consistente en el cobro de dos reales que debía pagar cada botija y veinte reales cada barril de vino mezcal que el gobierno expidiera ${ }^{67}$.

Una vez que el gobernador Prisciliano Sánchez determina la ubicación del Instituto en el edificio donde antes se encontraba la Universidad, y ordena su remodelación, se programa su inauguración para enero de 1827. Sin embargo, no es hasta marzo de 1827, que por decreto del Congreso, se les suspenden los sueldos que disfrutan el capellán, sacristán, portero y campanero del templo de la Compañía, y que eran pagados por el Estado, para que este capital se invierta en acopiar materiales para el salón del Congreso ${ }^{68}$.

De igual manera el gobernador dispuso la construcción de un capitolio para las sesiones del poder legislativo en el antiguo templo de la Compañía de Jesús, que desde Carlos III había pasado a propiedad del Estado, encomendando la dirección de la obra al hábil arquitecto don José Gutiérrez ${ }^{69}$. Desgraciadamente ese mismo año, en los primeros días de diciembre le sobrevino al gobernador Sánchez una infección en un dedo que, por la absorción purulenta, le causó la muerte el 30 de diciembre de 1826. Después de sus honras fúnebres, y decretándose

64 Colección de Decretos, circulares y órdenes de los Poderes Legislativo y Ejecutivo del Estado de Jalisco, Guadalajara, Jalisco, Gobierno del Estado, Tipográfica de M. Pérez Lete, 1874, pág. 266, citado en Pérez Verdía, op. cit., pág. 307.

65 Pérez Verdía, op. cit., pág. 308.

66 José María Luis Mora, Obras sueltas de José María Luis Mora, ciudadano mexicano, Revista política, t. I, París, Librería de la Rosa, 1837, citado en Laura Edith Domínguez González, El Instituto de Ciencias del Estado de Jalisco, Guadalajara, UNED, Gobierno del Estado, 1987, pág. 23.

67 Laura Edith Domínguez GonzÁLEz, op. cit., pág. 24.

68 Colección de Decretos..., op. cit., pág. 35.

69 Navarrete, Compendio de la Historia de Jalisco, pág. 97, citado en Pérez Verdía, op. cit., pág. 311. 
riguroso luto de vestir por nueve días a los empleados y padres de familia de todo el Estado ${ }^{70}$, toma posesión del cargo el vicegobernador Juan N. Cumplido, y es éste quien inaugura el Instituto de Ciencias el 14 de febrero de 1827. Desafortunadamente este instituto sólo sobrevivió siete años ya que don Antonio Romero, gobernador interino del Estado, lo clausuro a mediados de 1834, alegando que:

al cabo de ocho [fueron siete ya que inició funciones el 14 de febrero de 1827] años de fundado el Instituto, no se veían los jóvenes instruidos que eran (sic) muy de esperar brillaran en sus facultades para honor de Jalisco y del mismo Instituto. Con esto se grababa al Estado con veinte y cuatro mil pesos ${ }^{71}$.

Según el informe que dirige Romero al presidente Santa Anna en agosto de 1835, menciona textualmente lo siguiente:

Por decreto del $1 .^{\circ}$ de septiembre del año próximo pasado (1834) extinguió en la capital del Estado el Instituto literario que se había establecido ocho años antes, con el objeto, según decían los que se interesaron en su creación, de proporcionar a la juventud sólidos y extensos conocimientos en literatura, y en ciencias, conforme al gusto y luces del siglo; pero que una amarga y triste experiencia probó demasiado a los jaliscienses de que en tal establecimiento se propusieron miras muy diversas sus autores, porque ni se explicaron en él las lecciones de una verdadera y sólida ilustración, ni se formaron jamás sus alumnos en las ciencias, sino por el contrario se convirtió en la escuela del filosofismo y de inmoralidad, muy del gusto, es verdad, de los hombres corrompidos del siglo; mas de ninguna manera de los fieles amantes de una sana filosofía, llegando a inspirar con esto tal horror a los padres de familia que no querían justamente la corrupción y pérdida de sus hijos, que tomaron el partido de dejarlos antes sin otra instrucción que la que ellos mismos pudieran darles, según sus principios, que permitir oír lecciones del Instituto ${ }^{72}$.

El Instituto de Ciencias desde su creación tuvo fuertes problemas financieros. A pesar del subsidio del gobierno y de las ayudas del «fondo provincial», los gastos excedían a los ingresos ya que éstos incluían las reformas al edificio que antes había ocupado la Universidad, planteamiento de cátedra en la institución,

70 Colección de Decretos..., op. cit., pág. 116.

71 «Informe del Excmo. Sr. D. J. A. Romero al Presidente de la República», en El tiempo núms. 107 a 112 de octubre de 1834, citado en Pérez Verdía, op. cit., pág. 352.

72 Informe dirigido por el Gobierno de Jalisco al Excmo. Presidente, a consecuencia de la circular mandada por el Ministerio de Relaciones al mismo en 20 de agosto del presente año (1835), citado en Laura EDith Domínguez González, op. cit., pág. 27. 
pago de profesores y empleados, compra de instrumentos y formación de laboratorios, de bibliotecas, etc. En el primer año de funciones del Instituto (1827) el presupuesto aprobado fue de $\$ 33,339.00$ pesos incluyendo sueldos del personal docente y administrativo, reparación de fincas, y planteacion (sic) de cátedra. Se invierte a su vez $\$ 5,000.00$ en compra de libros para la biblioteca. Los sueldos de los profesores en los años 1829 a 1831 sufrieron fuertes detrimentos: el del presidente del Instituto que en 1829 fuera de dos mil quinientos pesos, en 1831 se vio reducido a mil doscientos pesos (percepción anual). De igual manera a los dos auxiliares de dibujo, que estaban a cargo de Gutiérrez, se les suprimen sus plazas a partir de $1831^{73}$.

En esta forma, el Instituto, inicia sus funciones con los profesores nombrados por el gobernador Prisciliano Sánchez, quienes recibieron su cargo de carácter de propietarios tal como lo ordenaba la legislación del mismo, nombrándose director al profesor Pedro Lissaute, francés de ideas liberales, y que al mismo tiempo fungía como catedrático de matemáticas. En el caso de Gutiérrez, según Pérez Verdía, se le nombró profesor honorario para que enseñara arquitectura, materia que formaba parte de la Academia y quien tendría como auxiliares a Santiago Guzmán y Sebastián Salazar. No sabemos si fue un error de Verdía ya que se le nombra desde un principio profesor propietario vitalicio. A este respecto encontramos en los Archivos del Congreso del Estado la relación de una disputa donde se encuentra implicado como profesor propietario a José Gutiérrez: José María Iriarte, profesor de la Academia en 1831, escribe al vicegobernador José Joaquín Herrera el 15 de septiembre, donde manifiesta su molestia ante la necesidad de que los auxiliares de pintura, escultura y dibujo intervinieran, por lo menos, en lo que concernía a su materia ya que podrían exponer los problemas que surgieran dentro de las mismas con mayor claridad que el profesor propietario (José Gutiérrez):

[...] se diría que el profesor de la principal de la sección citada 11. a sección [la de la Academia que contenía dibujo, geometría, arquitectura, escultura y pintura] es el indicado para ello, pero adviértase que este no es más que un arquitecto y dibujante; mas no un pintor o un escultor [...] sus conocimientos, prácticas y teorías de estas artes, nunca pueden ser tan extensos y fundamentales como los que particularmente y por obligación deben tenerlos ${ }^{74}$.

\footnotetext{
$73 \quad$ Ibid., pág. 54-63.

74 Archivo del Congreso del Estado, Contestación que hace José María Iriarte a la nota del gobernador Herrera, fecha 5 de enero de 1831. Ramo gobernación, años 1829-1831, caja 121.
} 
Y seguía diciendo que fueran los auxiliares quienes aplicaran los exámenes a los alumnos y no el propietario como se venía haciendo, ya que «los exámenes serán solo en lo aparente, quedando muy imperfectos e ilusorios por la falta de conocimientos en la materia de los que examinaban [...]» ${ }^{75}$. Esta situación debió alterar sobremanera a Gutiérrez, al menospreciar públicamente sus conocimientos, provocando con esto se destituyeran a los dos auxiliares de escultura que él tenía. A pesar de estos sinsabores, en agosto de 1827, presentaron exámenes de arquitectura 23 alumnos, en 1828 se examinaron 10 alumnos, en 1829 se registran 12 alumnos, en 1830, 18 alumnos y en 1831 impartía cátedra a 11 alumnos. Tres años más tarde, (1834) se cierra el Instituto de Ciencias por primera vez, quedándose Gutiérrez sin trabajo como docente de arquitectura.

Regresando a Prisciliano Sánchez, éste ordena la reubicación de la sede del Congreso del Estado (1828), para lo cual se designó una comisión para que buscara el lugar ideal. La comisión estuvo constituida por Urbano Sanromán, presidente; Miguel Pacheco Calderón, tesorero; Santiago Guzmán, José Gutiérrez y Manuel Cervantes, secretarios; y suplentes Doroteo Reyes y José María Portugal. Aquí es importante aclarar que seguramente el José Gutiérrez que mencionan fue el arquitecto Gutiérrez objeto de esta investigación y que como parte activa de la comisión se vio favorecido en la asignación del proyecto mencionado $^{76}$. Otro dato relevante es que en el libro consultado El Poder Legislativo de Jalisco se menciona que esta comisión seleccionó, y el Congreso aprobó, la iglesia de la extinta Real Universidad de Guadalajara, con las «piezas anexas a ella», y donde el director de Academias del Instituto hizo el plano del proyecto de acondicionamiento del lugar, incluyendo el pórtico, el salón de sesiones, la sala de comisiones, la secretaría, archivo y biblioteca. En la circular emitida el 29 de abril de 1829 , se menciona que se le asignan $\$ 2500.00$, que se han ahorrado de las dietas que debieran pagarse en ese año a los diputados; $\$ 200.00$ de los sueldos de magistrados del Supremo Tribunal de Justicia; $\$ 600.00$ del secretario de Gobierno, $\$ 6,300.00$ que producen las fincas y capitales que reditúan de la extinguida Universidad, más $\$ 2,000.00$ de la venta de los retablos de dicha iglesia, dando un total de $\$ 14,000.00$ pesos $^{77}$.

Se inician las obras con un presupuesto anual de $\$ 20,000.00$ pesos. En el Presupuesto General de Gastos del Estado de Jalisco, para el año 1827, se

75 Laura Edith Domínguez GonzÁlez, op. cit., pág. 70; consultar también Arturo CAmacho, «Documentos de la Academia de Bellas Artes de Guadalajara», en Memoria del Museo Nacional del Arte. núm. 8, Reproducciones Fotomecánicas, 2000, págs. 21-39.

76 El Poder Legislativo de Jalisco, notas históricas y funcionamiento, Guadalajara, Congreso del Estado de Jalisco, 2001, pág. 30.

77 Colección de Decretos, op. cit., pág. 87. 


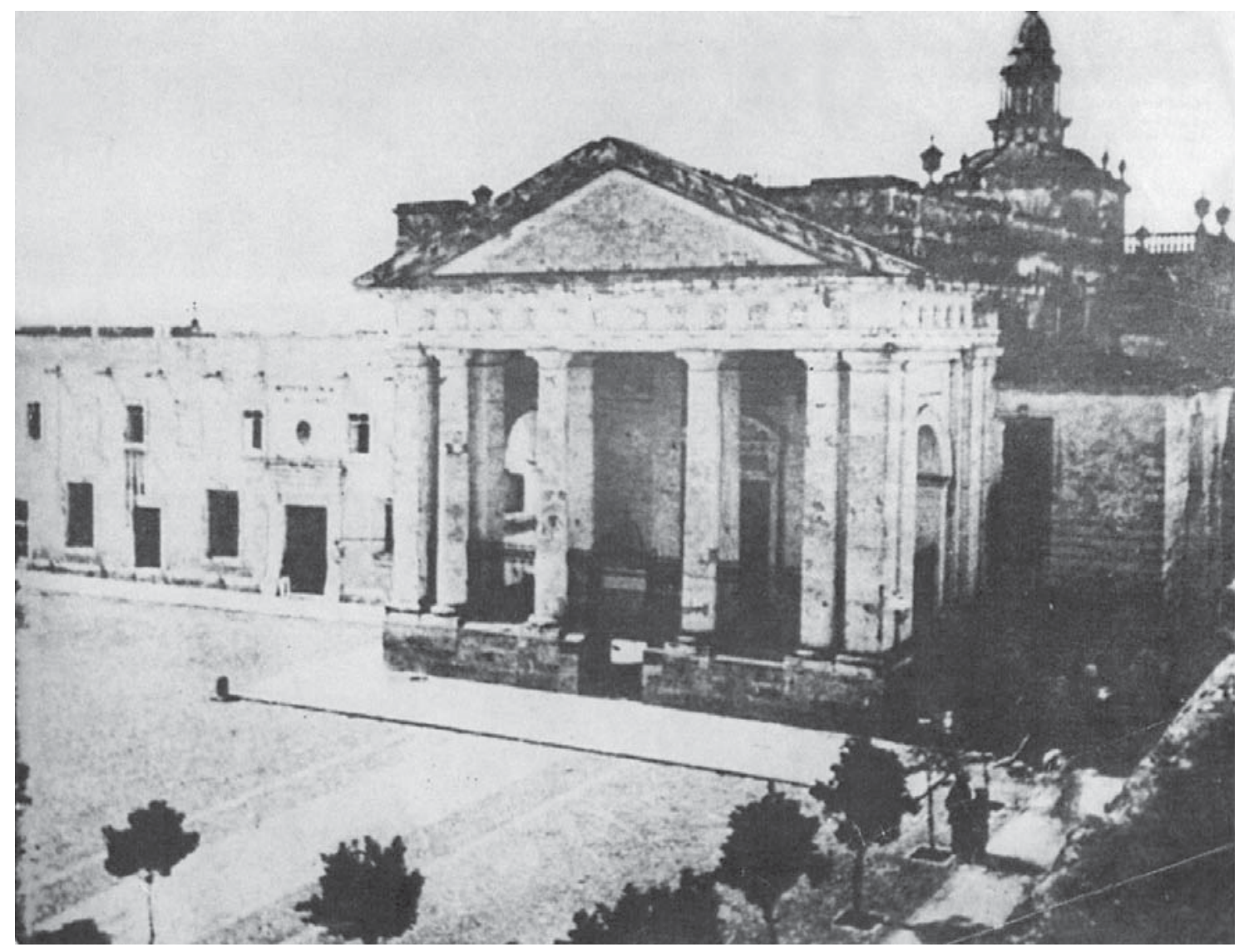

Ex-pórtico de Santo Tomás

aprueba la cantidad de $\$ 36,339.20^{78}$, y en el presupuesto de 1828 , se asignan las cantidades de $\$ 32,020.00$ para pago de sueldos de profesores y gastos ordinarios del Instituto, $\$ 20,000.00$ para la construcción del edificio del honorable Congreso y $\$ 1,176.00$ para las fincas del Instituto ${ }^{79}$. Todavía en septiembre de ese año el Congreso aprueba la asignación de \$228.00 para la habilitación de 66 estampas con marcos y vidrieras para la academia de dibujo y sala de yeso, donde Gutiérrez fungía como maestro vitalicio ${ }^{80}$. En el presupuesto de 1829, en la Colección de Decretos, todavía constatamos una partida destinada al pago de profesor de Academia, por la cantidad de $\$ 2,400.00$ y dos auxiliares por $\$ 1,200.00$ cada uno, mas $\$ 20,000.00$ para la conclusión del salón del honorable Congreso. Sin embargo, aunque en el papel la situación pareciera muy prometedora, la realidad era otra; la obra se suspende por conflictos gubernamentales, aunque afortunada-

\footnotetext{
Op. cit., pág. 106.

Op. cit., págs. 226 y 292.

80 Op. cit., págs. 118-120.
} 
mente para enero de 1832 se reinicia la construcción asignándosele $\$ 12,000.00$ del presupuesto de egresos del Estado. Sin embargo, con la inestabilidad que regía al Estado, esta construcción se suspendía continuamente. Finalmente el Congreso nunca sesionó en ese edificio, ya que en el gobierno de Ignacio L. Vallarta, se construye una sala de sesiones en el lado oriente del Palacio de Gobierno, inaugurándose ésta el 16 de septiembre de 1873.

Gutiérrez también vivió otra situación por demás apremiante: la llegada del cólera a Guadalajara en 1833. Esta enfermedad iniciada en Asia, se propaga a Rusia y de ahí a Polonia y Europa. El primer indicio de la misma se produce en Canadá en 1832 y hacia el mes de noviembre la enfermedad llega a Nueva Orleans para, posteriormente, ingresar en nuestro país por la vía de Tampico. El primer caso de cólera que se presentó en el interior del país fue en San Luis Potosí, el 28 de junio de 1833 y el 24 de julio muere en Guadalajara Saturnino Jiménez Cabello, de 10 años, quien vivía en el centro de la ciudad. Su acta de defunción fue registrada en la parroquia del Sagrario Metropolitano. Este hecho es importante si tenemos presente que Gutiérrez inició este templo antes de la Independencia y se suspende la obra cuando sólo le faltaba la cúpula, por lo que podemos deducir que ya para esta época se encontraba totalmente terminado y en funciones ${ }^{81}$. El martes 13 de agosto de 1833 la muerte asoló las calles de Guadalajara; en el transcurso de ese día doscientas treinta y ocho personas, después de soportar «terribles calambres y evacuaciones constantes» fallecieron víctimas de una enfermedad que nunca antes había conocido la población tapatía: el cólera morbus ${ }^{82}$, así lo dice Pérez Verdía en su Historia Particular del Estado de Jalisco, citando un número superior a los 3.255 muertes en el curso de los tres meses que se prolongó la enfermedad.

Otro hecho vendría a ensombrecer grandemente al arquitecto: el diputado Dr. D. Pedro Tamez presentó en sesión del Congreso de Jalisco del 18 de agosto de 1827, un proyecto de ley, por el cual todos los españoles en el término de veinte días, residentes en el Estado, salvo algunas excepciones, deberían salir de su territorio sin poder volver a él hasta que España reconociera la independencia de la República ${ }^{83}$. Esta ley se promulgó con el núm. 101, el 3 de septiembre de 1827 y se originaron graves trastornos. Luis Pérez Verdía externa su opinión ante la misma diciendo: «La expulsión de los españoles fue una medida injusta y antieconómica que a la vez rompía una de las garantías de Iguala, privaba al Estado de brazos y capitales útiles ${ }^{84}{ }$.

81 Lilia V. OLIVER, Un verano mortal, análisis demográfico y social de una epidemia de cólera, Guadalajara, 1833, Guadalajara, UNED, Gobierno de Jalisco, 1986, págs. 26-28.

82 Luis Pérez Verdía, op. cit., págs. 342-343.

83 Diario de las sesiones del Congreso, II, pág. 47, citado en Pérez Verdía, op. cit., pág. 317.

84 Pérez Verdía, op. cit., pág. 318. 
La suspensión de la obra de la sede del Congreso, el cierre del Instituto de Ciencias del Estado, la peste que se presenta en la ciudad así como la agresión sufrida ante la promulgación de la ley de expulsión de los españoles del Estado, seguramente mermó el ánimo y salud del arquitecto Gutiérrez. Su muerte acaeció en abril de 1835 a la edad de 69 años, aproximadamente, en la ciudad de Guadalajara y su cuerpo fue sepultado en el campo santo de Belén. Este dato es una aportación nueva a la vida de Gutiérrez ya que los anteriores historiadores manejaban la versión de que había fallecido en la ciudad de México, por el escrito enviado a la Academia de San Carlos por su esposa Guadalupe Carballo de Gutiérrez, solicitando ayuda económica por la difícil situación económica en que se encontraba al fallecer su marido ${ }^{85}$.

\section{Conclusión}

A lo largo de esta lectura hemos conocido a José María Gutiérrez López. Desde su llegada a la Nueva España, en 1787 a la edad de 21 años de edad, donde posteriormente logra titularse, con grandes sacrificios y penurias económicas, pero con la ilusión de empezar su vida profesional y destacar, como arquitecto egresado de la Academia de San Carlos, dispuesto a cosechar los reconocimientos sociales, económicos y académicos que por esto le correspondían.

Sin embargo, la sombra de sus maestros, tanto Ventura Rodríguez como del gran Tolsá, opacan su desempeño, y todavía le quitan su título durante 14 meses por causa del egocentrismo de su maestro Rodríguez. Esto será una mancha muy difícil de borrar tanto a nivel personal como dentro de su currículum académico. La situación le llevó a convertirse en un maestro muy exigente, como lo constatamos en los escritos de sus alumnos Manuel Pevedilla y José Mariano Domínguez de Mendoza quejándose de las persecuciones del director Gutiérrez.

Así pues, cuando le llega la solicitud de trasladarse a Guadalajara a realizar un trabajo importante, se le abrieron — según nuestro entender- nuevas expectativas para iniciar su actividad profesional lejos del ambiente opresivo de la Academia, y de los iconos de la misma. Llega a la Nueva Galicia, con toda la intención de desempeñarse excelentemente, e inicia la construcción de la Casa de la Misericordia, al tiempo la del templo del Sagrario, y por las noches imparte clases de dibujo y aritmética. Para desconsuelo de Gutiérrez, se inicia el movimiento de la Independencia y, como buen español, apoya a las tropas de

85 Eduardo Báez Macías, Guía del Archivo de la Antigua Academia de San Carlos 1801-1843, México, UNAM, 1972, gaveta 16, n. $^{\circ} 2.494$. 
Calleja, en calidad de artillero, en la batalla de Calderón. Fue encarcelado y despojado de todos sus bienes, y sin la posibilidad de terminar las obras iniciadas ya que su gran protector, el obispo Cabañas, también huye de la ciudad, por lo que decide volver a la ciudad de México donde solicita de nuevo su ingreso a la Academia. Afortunadamente, es nombrado director de arquitectura de la Academia de San Carlos, y se dedica a enseñar a sus alumnos con tenacidad y dedicación, constatando esto en la calidad de los dibujos de sus alumnos, que llevan la rúbrica del mencionado arquitecto. Sin embargo, debido al carácter rigorista de Gutiérrez, tiene enfrentamientos con sus compañeros de trabajo, y posteriormente con los directivos de la Academia, al no aceptar que docentes de otras disciplinas califiquen los planos que él autoriza. La Junta lo amonesta seriamente amenazándolo con quitarle el puesto de director, lo que amedrenta al arquitecto ya que se encontraba en una situación económica muy difícil, debido a que tres años antes le habían quitado todos sus bienes al no poder pagar el alquiler de la casa que habitaba junto con su esposa. El ambiente dentro de la Academia se vuelve muy difícil y cuando le llega de nueva cuenta la posibilidad de trasladarse a Guadalajara, como docente de arquitectura en el Instituto de Ciencias del Estado, acepta gustosamente.

Inicia su cátedra de arquitectura, el primer maestro de arquitectura en el occidente de México, y posteriormente se le asigna la construcción del pórtico de la nueva sede del Congreso; sin embargo ni los sueldos llegaban con puntualidad ni las remesas de dinero para la construcción de la sede del Congreso, lo que le seguía provocando vivir continuamente con penurias económicas. También vuelve a discutir, esta vez con sus ayudantes de dibujo y escultura, y como académico se torna todavía más exigente. Por la inestabilidad gubernamental en el Estado se cierra el Instituto, vive las atrocidades causadas por el cólera, y el menosprecio hacia los españoles con la ley promulgada para su expulsión del Estado, lo que definitivamente mina su salud.

Pareciera su vida una serie de contradicciones y conflictos uno tras otro. Sin embargo y a pesar de los altibajos, su tenacidad y perfeccionismo como académico no pueden discutirse, su capacidad innovadora dentro de un nuevo estilo se nota al diseñar todos sus proyectos en estilo neoclásico, y debemos ensalzar su valentía al cambiar la imagen urbana de una ciudad provinciana en tres edificios emblemáticos de la misma. 